\title{
0 importante é publicar. A (re)produção do conhecimento em educação física e ciências do desporto nos países de língua Portuguesa'
}

\author{
Adroaldo Gaya 2 \\ https://doi.org/10.5628/rpcd.10.01.200
}

\author{
Universidade Federal do Rio Grande do Sul \\ Escola Superior de Educação Física \\ Porto Alegre \\ Brasil
}

\section{INTRODUÇÃO}

A peruca é o símbolo mais apropriado para o erudito puro. Trata-se de homens que adornam a cabeça com uma rica massa de cabelo alheio porque carecem de cabelos próprios. Artur Schopenhauer(6)

A epígrafe dá o tom do presente ensaio. Devo prevenir o leitor de que o texto que segue, embora repleto de sinceridade e paixão, provavelmente terá gosto amargo. Principalmente ao sabor de alguns jovens cientistas e seus professores que confessam e partilham o paradigma epistemológico hegemônico em nossas faculdades. O paradigma que se funda no modelo de ciência que vou denominar de "modelo produtivista da ciência".

Há pessoas que simplesmente vivem da ciência: para eles, a ciência não passa de "uma boa vaca que lhes fornece leite." (6, p.25)

\section{Sequer percebem;}

Que a ciência que criamos é apenas isso, nossa criação. Mesmo que maravilhosa, será sempre limitada pelo que podemos conhecer do mundo. E como nunca poderemos conhecer tudo o que existe, nossa ciência será sempre incompleta. (3, p. 217)
Desculpem a ousadia. Mas, como nos ensina Umberto $\mathrm{Eco}^{(2, \text { p.11), }}$

Se alguém se abate por uma escolha política, civil ou moral (e no meu caso uma escolha epistemológica) tem o direito-dever de estar disposto a mudar de opinião. Mas no momento em que critica tem de estar convencido de que a razão está do seu lado, para poder denunciar energicamente o erro daqueles que tem o comportamento diferente do seu.

De minha parte, estou convencido das idéias que passo a defender. E, neste ensaio sobre os desafios da internacionalização de nossa comunidade científica de ciências do desporte e educação física de língua portuguesa, apresento uma tese principal de onde decorrem três hipóteses orientadoras:

TESE: A Ciência que não está ao serviço da vida, em todas as suas formas, é eticamente insustentável.

\section{HIPÓTESES:}

1. O modelo de formação de pesquisadores e de produção do conhecimento científico que, a meu ver, estamos consolidando em nossos cursos de graduação e pós-graduação, fundamenta-se num produtivismo que privilegia a prática de uma ciência alienada 
de valores epistemológicos e éticos.

2. Centrando-se predominantemente na produção de artigos para revistas internacionais, ditas de alto impacto, estamos submetidos a um sistema arbitrário que nos impõe uma vassalagem aos ditames das grandes corporações científicas internacionais (leiase editores científicos), onde somos forçados a nos submeter a uma verdadeira ditadura de métodos e de conteúdos. Enfim, só se pesquisa o que se pode publicar e, por outro lado, só se publica o que os editores internacionais permitem.

3. Nestas condições, seguindo a reboque das grandes corporações científicas internacionais e limitandonos às fronteiras de um dogmatismo epistemológico produtivista, dificilmente alcançaremos algum reconhecimento e, como tal, permaneceremos na periferia da comunidade científica internacional.

Sustentarei essas conjecturas por meio de breves sentenças morais. Entremeando convicções teóricas e exemplos concretos extraídos de nossa realidade, escreverei em linguagem direta e sem subterfúgios. Pretendo desmitificar alguns credos que se repetem em nossa academia como se fossem verdades absolutas. Pretendo desvendar mistérios para que possamos enxergar além dos limites restritos de um fazer científico que se orienta por princípios de um pragmatismo exagerado, onde o que realmente interessa é obedecer a uma política produtivista que se mantém restrita a modelos epistemológicos reducionistas e pouco criativos. Tocarei em pontos nevrálgicos.

Daí, o meu alerta inicial. Talvez este ensaio não seja agradável aos cientistas da moda, mas tenho a convicção de sua necessidade.

1

Permitam-me iniciar com uma longa, mas reveladora citação, retirada do excelente romance de Peter Bieri, que o escreveu sob o pseudônimo de Pascal Mercier, o Trem Noturno para Lisboa ${ }^{(4)}$. Logo no início, na página 33, encontramos o seguinte texto atribuído a um dos personagens da história (um pretenso escritor português de nome Amadeu de Prado, autor de um também pretenso livro: $O$ ourives das palavras). Quando leio jornal, escuto rádio ou presto atenção no que as pessoas dizem no café, sinto cada vez mais um enfado, um asco mesmo das palavras sempre iguais que são escritas ou ditas, sempre as mesmas expressões, sempre os mesmos floreios, as mesmas metáforas. (...) Essas palavras estão terrivelmente gastas e usadas, esgotadas pelos milhões de vezes em que foram usadas. Terão ainda algum significado? (...) A questão é: será que elas ainda exprimem pensamentos? Ou apenas formações sonoras que impelem as pessoas de um lado para o outro porque iluminam os traços de uma eterna tagarelice.

\section{2}

O que dizer de nossas tagarelices científicas?

\section{3}

Será que esse modelo hegemônico de ciência que exercitamos expresso numa tagarelice tão monótona quanto sofisticada, permite que possamos acessar nosso cérebro antes de ligar nosso computador? Ou será que andamos escravizados por modismos teóricos, metodológicos, epistemológicos que nos conduzem a reproduzir idéias que nos são impostas pelas corporações científicas internacionais?

\section{4}

Onde somos originais? Onde se materializa nossa criatividade? Onde nos livramos da ditadura do método? Quando deixamos de tagarelar sempre as mesmas formas de dizer as mesmas coisas? Enfim, quando "ligamos" nossos cérebros?

\section{5}

Lembremos que uma atividade criativa, como sugere Umberto Eco (op.cit.), é aquela que produz algo de inédito, que a comunidade está disposta a reconhecer como tal, aceitá-la, fazer sua e a reelaborar. Além do que, como nos lembra Peirce (apud, Eco, idibid.), se torna patrimônio coletivo, à disposição de todos, subtraído ao gozo pessoal.

\section{6}

\section{A ciência produtivista}

A ciência deve estar a serviço da humanidade. A ciência não deveria ser utilizada predominantemente como meio de afirmação pessoal ou como forma de satisfazer vaidades. Devíamos dar menos valor ao gozo pessoal. Todavia, em nossas faculdades adotamos uma política de pesquisas que se configura num palco de disputas e concorrências que chegam às 
raias do inadmissível. É o modelo produtivista de ciência. Nele o que interessa é publicar. Publicar muito.

\section{7}

Mas, convenhamos! Em nossas publicações estaremos realmente produzindo conhecimentos ou, em verdade o que fazemos é publicar em língua inglesa reproduções dos estudos realizados no estrangeiro com amostras de portugueses, brasileiros, moçambicanos, angolano...?

\section{8}

Basta uma breve revisão nas publicações de nossa ciência no Brasil, em Portugal, Moçambique..., para percebermos que nossos estudos não decorrem principalmente das necessidades inerentes às populações locais, mas da necessidade de nos aproximarmos do primeiro mundo da ciência. Eis um aspecto ético do maior significado. Mais importante do que investigar problemas de pesquisa realmente relevantes para a nossa realidade, a nossa cultura e para o nosso povo, é obter autorização para publicar nas revistas internacionais de alto impacto.

\section{9}

Talvez imaginemos que nada temos a acrescentar ao mundo desenvolvido da ciência. Mas, cabe a pergunta: será que nada temos para investigar, que, sendo fruto de nossa criatividade e compromisso com nossa gente, possa constituir conhecimento original e relevante? Quando vamos realmente produzir conhecimentos, ao invés de seguirmos reproduzindo o que se faz lá fora e que nem sempre nos diz respeito?

\section{0}

\section{Um mundo de vaidades}

Infelizmente. Vaidosos que somos, atribuímos peso demais às nossas conquistas. Iludidos pelo nosso sucesso, imaginamos que essas verdades parciais são parte de um grande quebra-cabeça, componentes de uma Verdade Final, esperando ser desvendada(3, p. 25).

\section{1}

Já é hora de enfrentarmos algumas evidências. Em primeiro lugar, basta um olhar à nossa volta para verificarmos que a comunidade científica, em grande parte, se configura num mundo de vaidades. Nossa comunidade de língua portuguesa não é diferente. Habitamos um mundo onde ocorrem acirradas lutas entre sujeitos e grupos de sujeitos pelo glamour de ter seus nomes registrados em revistas internacionais de alto impacto, de poder anunciar cientistas famosos como amigos "íntimos", obter financiamentos para sofisticados laboratórios que se tornam bunkers de pequenos grupos.

\section{2}

A vaidade é a inconsciência da estupidez - diz-nos o pretenso escritor português Amadeu Prado no romance de Pascal Mercier(4), atrás referido.

\section{3}

Atenção! Que fique claro: não estou advogando para abandonarmos a busca incessante pela qualidade do trabalho científico que nos leve ao cenário internacional. Não se trata de criticar o desejo de publicarmos em revistas científicas prestigiadas. O que estou afirmando é que o caminho para lá chegarmos é indevido.

\section{4}

A produção em periódicos com índices de impacto A vaidade também se manifesta na interpretação sobre o significado de impacto de uma pesquisa científica. Para esses pesquisadores o impacto de um estudo não está nos benefícios sociais e culturais que ele produz na população cuja amostra constituiu-se em cobaia para o grupo de investigadores. $\mathrm{O}$ impacto que realmente lhes interessa é o da revista onde o artigo será publicado.

\section{5}

Assim, o que na vida acadêmica deveria ser cooperação, solidariedade e respeito, passa a ser concorrência desenfreada, corporativismo de grupo e desrespeito da ética da convivência coletiva.

\section{6}

Precisamos admitir que nossa comunidade das ciências do desporto e de educação física de língua portuguesa não será reconhecida na comunidade internacional se não criarmos uma identidade. Não seremos percebidos na comunidade científica, se não 
produzirmos conhecimentos originais. Tenho a convicção de que não será apenas reproduzindo e replicando pesquisas que vamos obter reconhecimento. Certamente, não será apenas colaborando com pesquisadores de renome e fornecendo nossa mão de obra (ou de nossos alunos) e nossa gente como cobaias para replicação de estudos que obteremos reconhecimento da comunidade científica.

\section{7}

\section{Um mundo de disputas}

Na edição do XII Congresso de Ciências do Desporte e Educação Física dos Países de Língua Portuguesa, realizado em Porto Alegre anunciei alguns fatos que insistem em ficar escondidos, à sombra de um discurso público, que sugerem sentimentos de solidariedade, cooperação e respeito mútuo, mas que na verdade dissimulam acirradas disputas entre pesquisadores e grupos de pesquisadores no espaço lusófono.

\section{8}

\section{0 descrédito no trabalho alheio}

Falamos em comunidade das ciências do desporto e educação física dos países de língua portuguesa. Mas será que podemos realmente acreditar nesse discurso? Será que nossa comunidade vai além dos encontros sociais em que celebramos nossa amizade em abraços fraternos? Conseguimos ir além das edições de nossos congressos e alguns livros onde reunimos virtualmente (tudo é feito pela internet) autores que sequer lêem uns aos outros?

\section{9}

Conseguimos entre Brasil, Portugal e Moçambique, de início, uma boa experiência de mobilidade discente e docente. Muitos estudantes de graduação e mestrado atravessaram oceanos. Realizamos um doutoramento em parceria UP, USP e UFRGS. Professores cruzaram o Atlântico para ministrar aulas e conferências numa e noutra margem. $\mathrm{E}$ daí para frente? $\mathrm{O}$ que realizamos efetivamente que possa nos fortalecer frente à comunidade internacional?

\section{0}

Como imaginar uma cooperação efetiva no espaço da língua portuguesa com tantas vaidades e sentimentos de superioridade que se manifestam de lado a lado e que se mostram em vários cenários? Vou enumerar alguns exemplos. Sei que revelarei comportamentos e atitudes constrangedoras. Evidentemente, anunciarei os milagres, mas não vou identificar os santos. Colegas tenham certeza, o que lhes relato é retirado da vida real, ocorre em trabalhos publicados, em simpósios, nos gabinetes, em sala de aula, nos corredores e em mensagens de e-mail que, ao longo de quase 20 anos, tenho acompanhado.

\section{1}

Consultem os trabalhos publicados de nossos principais autores. Autores de uma mesma área de pesquisa. Área da atividade física e saúde, por exemplo, e tentem encontrar nos trabalhos de pesquisadores portugueses citações de autores brasileiros e viceversa. É muito raro. Já disse em Porto Alegre e repeti em Maputo $^{3}$, nós não nos lemos. Não valorizamos nossos pares. Não acreditamos em nossa própria capacidade de produzir conhecimentos. No entanto, principalmente portugueses e brasileiros publicam com muita frequência em periódicos internacionais ditos de alto impacto. Basta uma breve consulta nos principais indexadores científicos para verificarmos essa afirmação.

\section{2}

O que dizer quando um orientador de doutorado de um estudante brasileiro sugere que seu aluno retire autores brasileiros de sua tese, argumentando que tais autores não possuem representatividade científica? Percebam o absurdo. Não é o conteúdo das pesquisas que interessa, mas o status do pesquisador e, principalmente, se ele fala, escreve, é de origem ou reside num espaço não lusófono.

\section{3}

O que pensar quando congressos internacionais de grande relevância são realizados no Brasil e em Portugal, sem a presença de convidados portugueses no Brasil e convidados brasileiros em Portugal? E sem a presença de moçambicanos num e noutro país?

\section{4}

Será que o sonho da comunidade das ciências do desporto e educação física dos países de língua portuguesa limita-se apenas aos nossos congressos? 


\section{5}

\section{Dissertações e teses}

O produtivismo científico atingiu em cheio a formação de professores. Nossas dissertações e teses já não são mais monografias que permitem aos nossos mestrandos e doutorandos um aprofundamento teórico e metodológico. O que importa é publicar, em co-autoria com orientador e os colegas de grupo, três, quatro ou cinco artigos para "engordar" o currículo acadêmico dos pares.

\section{6}

Quando participarmos de um júri de mestrado ou doutorado, já não sabemos mais quem estamos avaliando. Será o estudante que está perante o júri a apresentar o trabalho ou será o orientador, orientadores ou um grupo de pesquisa?

\section{7}

Os programas de pós-graduação já não se preocupam com a formação de pesquisadores. Os programas se preocupam em produzir artigos, independente se os mestrandos e doutorandos, quando concluem os cursos, terão capacidade para seguirem suas vidas acadêmicas com autonomia intelectual e criatividade.

\section{8}

Hoje em muitos júris de mestrado e doutorado a primeira pergunta de um arguente é a seguinte: em que revista você pretende publicar os resultados de sua dissertação ou tese? E a partir da resposta do candidato se desenvolve a argüição, tendo como parâmetro de qualidade as exigências dos editores do referido periódico científico.

\section{9}

\section{E o modelo produtivista de ciência} contaminou os cursos de graduação

O modelo produtivista atingiu em cheio os cursos de formação professores de educação física, principalmente nas grandes universidades, onde a pesquisa é atividade inerente à formação e, diga-se de passagem, é tratada com muita competência.

\section{0}

Dessa contaminação resultaram, entre outras, duas conseqüências que estão diretamente relacionadas com a formação científica dos graduandos: $\left(1^{\circ}\right)$ ou a iniciação científica induz o estudante de graduação a tornar-se um pesquisador precocemente especializado numa determinada disciplina científica; $\left(2^{\circ}\right)$ ou a iniciação científica faz do estudante de graduação mão de obra para aumentar a produção científica de seus orientadores.

\section{1}

No primeiro caso, o estudante de graduação se integra aos grupos de pesquisa e passa a ter uma formação científica disciplinar altamente especializada (muito competente, sem dúvida!). É comum observarmos que, na medida em que este aluno obtenha sucesso, logo ao final do curso de graduação realizará seu mestrado, ato contínuo, seu doutorado e, como tal, será um doutor em educação física, sem sequer ter dado aulas de educação física. Isto, se ainda não fizer um concurso para a carreira universitária e, em consequência do peso atribuído à sua produção científica, for aprovado e acabe ministrando aulas nos cursos de formação de professores de educação física.

\section{2}

No segundo caso, a situação é mais grave. O estudante, servindo como mão de obra num laboratório ou gabinete de um grupo de pesquisadores mais experientes, realiza tarefas específicas para auxiliar os mestrandos e doutorandos do orientador e, como tal, não segue um percurso devidamente planejado para sua formação científica. Produz um trabalho de conclusão de curso de graduação (TCC) ${ }^{4}$ em coautoria com vários estudantes de pós-graduação e o respectivo orientador, sem, no entanto, aprender os caminhos para a sua autonomia científica. Torna-se um escravo de técnicas e métodos de pesquisa que seus colegas mais experientes lhe apresentaram de forma acrítica num programa de computador onde digita comandos que lhe fornecem dados, sem sequer compreender o respectivo significado.

\section{3}

É fácil concluir que tais caminhos nos distanciam da formação pedagógica em educação física e esportes. A pesquisa deixa de ser um instrumento de autonomia para a produção do conhecimento. A especializa- 
ção disciplinar precoce limita os horizontes do estudante. Ele passa a ver o mundo através de uma janela única. Uma janela estreita. Reduz o mundo às fronteiras da sua disciplina. Assim, a educação física e os conhecimentos sobre as práticas desportivas implodem em fragmentos de fisiologia, biomecânica, bioquímica, psicologia, sociologia, antropologia; e correm o risco de nunca encontrar sua matriz transdisciplinar.

\section{4}

Considerando minha experiência como professor de epistemologia e metodologia da pesquisa em cursos de graduação e pós-graduação em educação física, me preocupo com os rumos que a produção científica tem seguido já a partir do TCC de graduação. Afinal, nossos cursos de graduação formam professores de educação física ou pesquisadores profissionais?!

\section{5}

A pesquisa nos cursos de graduação é um instrumento para propiciar ao professor produzir conhecimentos que possam dar sustentação à sua prática pedagógica? Ou será uma nova especialização profissional com fim em si mesmo?

\section{6}

O que se torna mais relevante num curso de graduação em educação física? Formar um bom professor? Ou formar um excelente pesquisador mesmo que não saiba ministrar aulas?

\section{7}

Tenho a convicção de que o objetivo dos cursos de graduação em educação física é formar bons professores de educação física. Sendo assim, é neste contexto que se deve pensar a finalidade da formação científica do estudante de graduação.

\section{8}

Há certamente unilateralidades e parcialidades, quiçá algum excesso, nas tintas desta análise; mas exagerar é uma maneira de alertar, de mostrar contradições, insuficiências, superficialidades e derivas numa conjuntura que acentua e enfatiza o culto da vaidade e ignora tantos outros valores relevantes. Importa, sobretudo, que nos interroguemos se não estamos possuídos de uma mentalidade meramente pragmática e (re)produtivista, onde os objetivos da produção do conhecimento científico se limitam a dar prestigio ao nosso currículo acadêmico, insuflar nossos egos, independentemente do significado e do compromisso humano de nossas pesquisas ${ }^{5}$.

\section{9}

\section{Em forma de conclusão}

O valioso tempo dos maduros

Mário de Andrade

Contei meus anos e descobri que terei menos tempo para viver daqui para a frente do que já vivi até agora.

Tenho muito mais passado do que futuro.

Sinto-me como aquele menino que recebeu uma bacia de cerejas.

As primeiras, ele chupou displicente, mas percebendo que faltam

poucas, rói o caroço.

Já não tenho tempo para lidar com mediocridades.

Não quero estar em reuniões onde desfilam egos inflados. Inquieto-me com invejosos tentando destruir quem eles admiram,

cobiçando seus lugares, talentos e sorte.

Já não tenho tempo para conversas intermináveis, para discutir

assuntos inúteis sobre vidas alheias que nem fazem parte da minha.

Já não tenho tempo para administrar melindres de pessoas, que apesar

da idade cronológica, são imaturos.

Detesto fazer acareação de desafetos que brigaram pelo majestoso cargo

de secretário geral do coral.

'As pessoas não debatem conteúdos, apenas os rótulos'.

Meu tempo tornou-se escasso para debater rótulos, quero a essência,

minha alma tem pressa...

Sem muitas cerejas na bacia, quero viver ao lado de gente humana,

muito humana; que sabe rir de seus tropeços, não se encanta com

triunfos, não se considera eleita antes da hora, não foge de 
sua mortalidade,

Caminhar perto de coisas e pessoas de verdade,

$O$ essencial faz a vida valer a pena.

E para mim, basta o essencial!

\section{0}

Talvez a deselegância de minhas palavras decorra da impaciência de quem tem apenas poucas cerejas na bacia. Já não tenho tempo para compartilhar de vaidades e seguir por caminhos que nos trazem sempre de volta ao mesmo lugar. Sonho com o dia em que nossa comunidade científica seja respeitada pelo que produz e não pelo que reproduz. Portanto, sinto ser meu dever denunciar o que entendo como um descaminho. São: o apego ao ideal da lusofonia e ao princípio da responsabilidade, a força anímica que motivam a minha militância e inflamam o meu discurso.

\section{1}

Na investigação do conhecimento eu não sinto mais do que a alegria da minha vontade, a alegria de engendrar; e se há inocência em meu conhecimento, é porque há nele vontade de ser fecundado (5, p.120).

\section{NOTAS}

${ }^{1} \mathrm{O}$ presente ensaio é uma adaptação da palestra conferida pelo autor durante o XIII Congresso de Ciências do Desporto e de Educação Física dos Países de Língua Portuguesa, realizado em Maputo (Moçambique), de 30 de Março a 2 de Abril de 2010. ${ }^{2}$ Professor Titular do Departamento de Educação Física e do Programa de Pós-graduação em Ciências do Movimento Humano da UFRGS. Doutor em Ciências do Desporto pela UP. Pesquisador 1D CNPq. Membro do Comitê de Ética em Pesquisa da UFRGS e Coordenador do Projeto Esporte Brasil. ${ }^{3}$ Durante o XIII Congresso de Educação Física e Ciências do Desporto dos Países de Língua Portuguesa.

${ }^{4}$ TTC é como são conhecidos os trabalhos de conclusão de cursos de graduação em educação física no Brasil Trata-se de uma monografia de caráter científico que o aluno deve apresentar a um júri como requisito parcial para sua colação der grau.

${ }^{5} \mathrm{O}$ texto original é de Jorge Bento em outro contexto de análise e foi adaptado ao presente ensaio. Bento JO (2010). Do

Corpo e do Activismo na conjuntura de mercado e consumo. Revista Portuguesa de Ciências do Desporto, 9 (2-3): 203-227

\section{REFERÊNCIAS}

1. Bento JO (2010). Do Corpo e do Activismo na conjuntura de mercado e consumo. Revista Portuguesa de Ciências do Desporto, 9(2-3): 203-227,

2. Eco U (2008). A passo de caranguejo. ( $6^{\mathrm{a}} \mathrm{ed}$.) Tradução de Ana Eduardo Santos. Lisboa: DIFEL,.

3. Gleiser M (2010). Criação Imperfeita. Cosmos, vida e o código oculto da natureza. Rio de Janeiro: Record

4. Mercier P (2009). O Trem Noturno para Lisboa. (4aed.) Tradução de Kristina Michahelles. Rio de Janeiro: Record

5. Nietzsche F (2009). Assim falava Zaratustra. Tradução de Mário Ferreira dos Santos ( $3^{\mathrm{a}}$ ed.) Rio de Janeiro: Vozes

6. Schopenhauer A (2009). A arte de escrever. Tradução de Pedro Süssekind. Porto Alegre: L\&PM 